Center for Behavioral and Community

Health Studies,

Graduate School of

Public Health, San

Diego State University,

San Diego, CA, USA

K B Weaver

S I Woodruff

T L Conway

C C Edwards

J P Elder

Department of Family and Preventive

Medicine, University of California, San

Diego, 9500 Gilman

Drive, La Jolla, CA,

USA

S-H Zhu

Correspondence to: Dr Susan I Woodruff, Graduate School of Public Health, San Diego State University, 9245 Sky Park Court, Suite 120, San Diego, CA 92123, USA. Telephone 001619594 2787; fax 001 619594 3143; email swoodruf@mail.sdsu.edu

Accepted 10 July 1998

\title{
Does the US Navy attract young women who smoke?
}

Kathleen B Weaver, Susan I Woodruff, Terry L Conway, Christine C Edwards, Shu-Hong Zhu, John P Elder

\begin{abstract}
Objective-To assess whether the United States Navy is disproportionately attracting and recruiting female smokers from the civilian sector.

Methods-Standardised comparisons of cigarette use among Navy women recruits and civilian women were conducted with data from a 1996-97 Department of Defense study and the 1994 National Health Interview Survey.

Results-Young Navy women recruits (18-22 years) had significantly higher rates of current and heavy smoking than their civilian counterparts after adjusting for differences in sociodemographic characteristics. Smoking rates among older recruits and civilian women (23-30 years) were not significantly different.

Conclusions-It seems that the Navy attracts young civilian women who already smoke, many of whom smoke heavily. (Occup Environ Med 1998;55:792-794)
\end{abstract}

Keywords: smoking; military; women; tobacco use

The civilian population has seen dramatic decreases in smoking rates in the past 30 years. ${ }^{12}$ Although this decreasing trend has also been evident in the United States military services, smoking rates remain higher among military personnel than among civilians. ${ }^{34}$ Tobacco use is of particular concern to the United States Navy as it is estimated that 35\% of Navy personnel are smokers compared with $25 \%$ of civilians. ${ }^{14}$ Studies in the 1980 s suggested that the military services were creating smokers rather than attracting them, and that military policies and programmes at the time had not been effective in reducing smoking. ${ }^{5}$ The present study considers the attracting part of the creating versus attracting question and focuses on women just entering the United States Navy. No studies to date have been conducted that focus exclusively on military women, and no studies have compared smoking rates among new military recruits and civilians. This paper reports the results of standardised comparisons of cigarette use among US Navy women recruits and their counterparts in the general population. By conducting standardised comparisons, the question of whether the Navy recruits female smokers can be answered more definitively.

\section{Methods}

DATA SOURCES

Navy women recruits

This study was part of a larger project sponsored by the Department of Defense to assess the long term effectiveness of two smoking relapse prevention strategies for Navy women. ${ }^{8}$ Data for Navy women recruits were taken from baseline surveys on tobacco use of all women entering basic training at the United States Navy Recruit Training Command at Great Lakes, Illinois during March 1996 to March 1997. Sociodemographic data were extracted from the computerised Navy enlisted master record (EMR). The record is maintained by the Bureau of Naval Personnel and is used in processing personnel information for all active duty Navy enlisted members.

Of the 5894 Navy women recruits eligible for participation in the study, a total of 5503 $(93 \%)$ completed a baseline survey. Baseline surveys were matched with sociodemographic data from the enlisted master record by social security number. Twenty four surveys could not be matched. Also, women who were aged 17 on entry into the recruit training $(n=325)$ were excluded from the present analysis due to incomparability with the female civilian population data. Women older than 30 were excluded because of low numbers $(n=73)$. Thus, 5081 surveys $(92 \%$ of the original surveys) were available for analysis.

\section{Civilian women}

Civilian data were extracted from the 1994 National Health Interview Survey, which collects information related to health on a yearly basis through face to face interviews with a sample from the civilian non-institutionalised population residing in the United States. The Year 2000 Objectives Supplement to the National Health Interview Survey was administered to one adult person per family in half of the households in the 1994 sample, and contains questions about tobacco use. A basic weighting was applied which reflects the probability of selection and household nonresponse, resulting in national estimates of 
Table 1 Sociodemographic characteristics of navy women recruits and civilian women, age 18-30

\begin{tabular}{|c|c|c|}
\hline Sociodemographic characteristic & $\begin{array}{l}\text { Civilian } \\
(n=2536) \\
\%\end{array}$ & $\begin{array}{l}\text { Navy } \\
(n=5081) \\
\%\end{array}$ \\
\hline \multicolumn{3}{|l|}{ Age: } \\
\hline 18-19 & 11.1 & 62.1 \\
\hline $20-22$ & 19.2 & 26.5 \\
\hline $23-30$ & 69.7 & 11.4 \\
\hline \multicolumn{3}{|l|}{ Race or ethnicity: } \\
\hline White, non-Hispanic & 67.0 & 58.2 \\
\hline Black, non-Hispanic & 16.5 & 23.2 \\
\hline Hispanic & 11.8 & 12.3 \\
\hline Other & 4.7 & 6.3 \\
\hline \multicolumn{3}{|l|}{ Education: } \\
\hline$<$ High school & 15.9 & 5.4 \\
\hline High school & 38.0 & 85.3 \\
\hline$>$ High school & 46.0 & 9.4 \\
\hline
\end{tabular}

Civilian percentages are based on cases from the 1994 National Health Interview Survey weighted to account for the probability of selection and household non-response.

smoking. The Year 2000 objectives supplement includes a total of 19738 interviews for a response rate of $79.5 \%$. Sociodemographic and cigarette use variables for all women between the ages of 18 and 30 were extracted from the National Health Interview Survey, for a total of 2536 cases. $^{9}$

STANDARDISATION PROCEDURES

Direct standardisation was used to adjust for sociodemographic differences between the two populations. ${ }^{10}$ Civilian data were standardised to the joint distribution in the population of Navy women recruits of race or ethnicity (white, black, Hispanic, other) and education (less than high school, high school, more than high school).

The DESCRIPT procedure in SUDAAN ${ }^{11}$ was used to handle the complex National Health Interview Survey sampling design and to produce standardised estimates and standard errors for the civilian data. Unstandardised estimates for Navy women recruits were compared with standardised estimates for the civilian women with a difference of proportions $z$ test. ${ }^{12}$ Comparisons are reported within three age strata: 18-19,20-22, and 23-30. These age groupings were chosen to represent older teens, women in their early $20 \mathrm{~s}$, and what would be considered relatively older women in the context of the military recruit population. Because there were few women recruits in their mid to late 20 s, it was not possible to look at finer age groupings.
MEASURES OF CIGARETTE USE

Navy and civilian women were categorised as smokers based on identical survey items. Those who reported smoking 100 cigarettes in their entire life and smoking in the past 30 days were classified as current smokers. ${ }^{4}$ Current smokers who reported smoking $\geqslant 16$ cigarettes a day were classified as heavy smokers.

\section{Results}

As shown in table 1, the Navy recruit population is younger, less educated, and somewhat more ethnically diverse, with larger percentages of African American and Hispanic women than the civilian population.

Results of the comparisons of current and heavy smoking between Navy women recruits and civilian women are presented in table 2 . Standardised comparisons for women 18-19 years old and those 20-22 years old were significant, with Navy women recruits having higher prevalences of current and heavy smoking in both of these age strata. For women 23-30 years old, differences in current and heavy smoking between the Navy and civilians were not significant.

\section{Discussion}

This report provides evidence that the United States Navy disproportionately recruits more young women who already smoke before entering military service. This is especially apparent among young women (aged 18-22). Even after controlling for race or ethnicity and education, young Navy women recruits had significantly higher smoking rates than their civilian counterparts. Among older women (ages 23-30), there was no significant difference in current or heavy smoking prevalence between the two populations after adjusting for sociodemographic factors.

Two limitations of the present study should be noted. Firstly, data for Navy women recruits were collected in 1996-7, whereas the data for civilian women were collected in 1994 . However, assuming that smoking rates among women have continued to show the gradual decline seen before $1994,{ }^{13}$ the results of this study are conservative - that is, the 1996-97 civilian smoking rates might actually be slightly lower than the 1994 rates used in these analyses. A second limitation is that these data sets were collected with different methods of survey

Table 2 Comparisons of current and heavy smoking among navy women recruits and civilian women by age group

\begin{tabular}{|c|c|c|c|c|c|c|c|c|c|c|}
\hline \multirow[b]{2}{*}{ Age group } & \multicolumn{5}{|c|}{ Current smoking } & \multicolumn{5}{|c|}{ Heavy smoking } \\
\hline & Navy & Civilian & Difference & $95 \% C I$ & $p$ Value & Navy & Civilian & Difference & $95 \% C I$ & $p$ Value \\
\hline \multicolumn{11}{|l|}{ 18-19: } \\
\hline$\%$ Yes & 35.5 & 16.7 & 18.8 & 14.2 to 23.6 & $\leqslant 0.001$ & 13.2 & 5.5 & 7.7 & 4.8 to 10.6 & $\leqslant 0.001$ \\
\hline SEM & 0.9 & 2.5 & & & & 0.6 & 1.6 & & & \\
\hline $\mathrm{n}$ & 3148 & 277 & & & & 3145 & 277 & & & \\
\hline \multicolumn{11}{|l|}{ 20-22: } \\
\hline$\%$ Yes & 40.9 & 29.5 & 11.4 & 6.5 to 16.3 & $\leqslant 0.001$ & 17.9 & 8.3 & 9.6 & 6.4 to 12.8 & $\leqslant 0.001$ \\
\hline SEM & 1.3 & 2.8 & & & & 1.0 & 2.0 & & & \\
\hline $\mathrm{n}$ & 1343 & 474 & & & & 1340 & 474 & & & \\
\hline \multicolumn{11}{|l|}{$23-30:$} \\
\hline \% Yes & 32.8 & 34.7 & 1.9 & -2.5 to 6.3 & NS & 14.5 & 11.1 & 3.4 & 0.2 to 6.6 & NS \\
\hline SEM & 2.0 & 1.7 & & & & 1.5 & 1.1 & & & \\
\hline $\mathrm{n}$ & 576 & 1725 & & & & 574 & 1723 & & & \\
\hline
\end{tabular}

Civilian estimates have been standardised to the Navy distribution of education and race or ethnicity.

Civilian data source: 1994 National Health Interview Survey. 
administration: the Navy recruit data were collected with self report questionnaires whereas the civilian data were collected in face to face interviews. These differences suggest caution in drawing conclusions from the present study.

Our results from the present study indicate that the Navy is dealing with a population of women who have high smoking rates from the outset of military service. Why the Navy may attract young smokers is not clear. Certain personality factors (sensation seeking, risk taking, rebelliousness, confidence) may play a part. There may be geographical differences such that women who come from regions with high smoking rates may join the Navy in disproportionate numbers. Unmeasured peer and parental factors-for example, veteran status of father-also may influence a young woman to smoke and to choose to join the Navy. Whatever the explanatory factors, however, this finding underscores the need for intensified programmmes directed towards stopping smoking during the recruit training period. Perhaps more importantly, there is a need to create expectations among potential recruits that the Navy environment is non-smoker friendly. In 1987, the United States Navy instituted a 24 hour smoking ban during the entire 8 week period of recruit training, and in 1994 the Navy became a smoke free workplace. These are important steps toward changing the Navy environment, which has historically tolerated (and perhaps promoted) smoking. However, more interventions are needed to change other aspects of Navy culture that may foster cigarette use. The military services have a unique opportunity to make a positive impact by reducing cigarette use among its recruits and personnel. Most people who enter military service return to the civilian sector after a relatively brief period of service. Thus, decreasing smoking rates among service personnel would reduce health related costs not only for the military service, but ultimately for the civilian sector as well.

This research was supported by the Department of Defense (DoD), Defense Women's Health Research Program (DAMD17-95-5075), and by the augmentation awards science and engineering research training (AASERT) grant No DAAH04-96-0116. We gratefully acknowledge Drs Stephe Bender and Richard Hough for their critique of earlier drafts of this manuscript.

1 Centers for Disease Control and Prevention. Surveillance for selected tobacco-use behaviors-United States, 190094. MMWR CDC Surveill Summ 1994;43:SS-3.

2 National Center for Health Statistics. Health, United States, 1995. Hyattsville, MD: Public Health Service, 1996.

3 Bray RM, Kroutil LA, Marsden ME. Trends in alcohol, illicit drug, and cigarette use among US military personnel: 1980-92. Armed Forces and Society 1995;21:271-93.

4 Bray RM, Kroutil LA, Wheeless SC, et al. 1995 Department of Defense survey of health related behaviors among military personnel. Research Triangle Park, NC: Research Triangle Institute, 1995.

5 Cronan TA, Conway TL. Is the Navy attracting or creating smokers? Mil Med 1988;153:175-8.

6 Bray RM, Marsden ME, Peterson MR. Standardized comparisons of the use of alcohol, drugs, and cigarettes among military personnel and civilians. Am f Public Health 1991;81:865-9.

7 Cronan TA, Conway TL, Kaszas SL. Starting to smoke in the Navy: when, where, and why. Soc Sci Med 1991;33: 1349-53.

8 Conway TL, Woodruff SI, Edwards CC, et al. Operation stay quit: smoking relapse prevention for Navy women recruits. Health Psychol 1996;18:4-5,24

9 Current estimates from the National Health Iinterview Survey, 1994. Vital Health Stat 10. 1996;193. (DHHS publication PHS 96-1521.)

10 Kalton G. Standardization: a technique to control for extraneous variables. Applied Statistics 1968;23:118-36.

11 SUDAAN (Software for survey data analysis) version 5.30 manual. Research Triangle Park, NC: Research Triangle Institute; 1989.

12 Fleiss JL. Statistical methods for rates and proportions. New York, NY: John Wiley, 1973.

13 Shopland DR, Hartman AM, Gibson JT, et al. Cigarette smoking among US adults by state and region: estimates from the Current Population Survey. 7 Natl Cancer Inst 1996;88: $1748-58$. 